\title{
A IMPORTÂNCIA DA AVALIAÇÃO DAS DOSAGENS DAS COLINESTERASES EM CASOS DE INTOXICAÇÕES POR ORGANOFOSFORADOS
}

\author{
Paula Vieira Marques ${ }^{1}$ \\ Bruno Tolentino Caixeta
}

\section{RESUMO}

Os agrotóxicos são amplamente utilizados nos setores agrícolas visando uma maior produtividade, porém essa utilização tem se tornado uma ameaça a saúde pública, principalmente para a população rural, devido à desinformação quanto à nocividade desses compostos à saúde humana e ao meio ambiente. A principal classe de inseticidas envolvidas nos casos de intoxicação é representada pelos organofosforados e os carbamatos, estes compostos causam a inativação das enzimas colinesterásicas, AChe e BChe, que levam a elevação de Acetilcolina, gerando uma série de manifestações nicotínicas, muscarínicas e no Sistema Nervoso Central. O artigo foi realizado através de pesquisa bibliográfica, que abrange toda bibliografia pública em relação ao tema estudado, como publicações de artigos científicos, monografias, dissertações e revistas eletrônicas, entre outras, localizadas em acervo digital através de sites relacionados. Concluiu-se com o trabalho, a necessidadede maior emprego de normas de segurança, como a utilização de EPI's durante o manuseio dos produtos, fortalecimento nos sistemas de notificações e informações aos agricultores sobre os organofosforados, realização de monitoramento dos níveis das colinesterases de agricultores, por meio de exames laboratoriais, para prevenção, diagnóstico e melhoramento de qualidade de vida, relacionada à saúde dos trabalhadores, evitando possíveis complicações.

Palavras-Chave: agrotóxicos, colinesterases, diagnóstico, intoxicação.

\section{ABSTRACT}

\footnotetext{
${ }^{1}$ Endereço eletrônico de contato: paulavieiramarques@hotmail.com.br
}

Volume 2, Número 1 - Maio, 2016. 
Pesticides are widely used in agricultural sectors seeking greater productivity, but such use has become a threat to public health, particularly for the rural population due to misinformation concerning the toxicity of these compounds to human health and the environment.The primary class involved in insecticide poisoning cases is represented by organophosphates and carbamates, these compounds cause inactivation of enzymes cholinesterase, AChE and BChE, leading to elevation of acetylcholine, generating a series of nicotinicmanifestations muscarinic and in the central nervous system. The article was based on a literature review, which covers all public literature on the topic studied, as publications of scientific articles, monographs, dissertations and electronic journals, among others, located in digital archives to related sites. The conclusion of this work is the need for greater job security standards, such as using EPI's when handling products, systems strengthening in the notifications and information to farmers on organophosphates, carrying out monitoring of levels of cholinesterase farmers, through laboratory testing, prevention and improvement of quality of life, health-related workers, avoiding possible complications.

Keywords: cholinesterases, pesticides, poisoning e diagnostic.

\section{INTRODUÇÃO}

Os agrotóxicos são substâncias utilizadas em diversas áreas dos setores agrícolas, divididos em grupos de acordo com a ação, sendo, herbicidas, fungicidas e inseticidas. A utilização desses produtos em países em desenvolvimento ganhou destaque a partir da década de 60 e no Brasil, país economicamente agrícola, deu-se a partir da década de 70 , por incorporação compulsória de adubos e fertilizantes em programas financiados pelo governo federal. ${ }^{(1,2,3)}$

Os inseticidas, entretanto, vêm representando uma grave ameaça à sociedade. Sua utilização extensiva vem se tornando um grave problema de saúde pública, principalmente a população rural, devido à desinformação quanto à nocividade desses compostos à saúde humana e ao meio ambiente. ${ }^{(4)}$

No Brasil, o SINITOX (Sistema Nacional de Informações Toxico-Farmacológicas) é o órgão responsável pelos registros de intoxicações, que fornece informações toxicológicas e farmacológicas sobre medicamentos e agentes tóxicos existentes em nosso meio. ${ }^{(5,6,7)}$

A principal classe de inseticidas envolvidas nos casos de intoxicação é representada pelos organofosforados e os carbamatos, estes possuem o mesmo mecanismo de ação, porém os primeiros, causam inibição irreversível das colinesterases e os segundos, causam inibições consideradas reversíveis. Sendo assim, os carbamatos são menos prejudiciais se comparados com os primeiros citados. ${ }^{(8,9)}$

Volume 2, Número 1 - Maio, 2016. 
Os organofosforados apresentam risco potencial aos seres humanos, devido à alta lipossolubilidade e a sua estrutura química, sendo então absorvidos pelo organismo através das mucosas, da via respiratória, da pele e do trato gastrointestinal, são metabolizados rapidamente e geram metabólitos hidrossolúveis, este processo faz com que os compostos se tornem ativos toxicologicamente. $(4,9,10)$

Esses compostos inativam as enzimas acetilcolinesterase plasmática que predomina no plasma, fígado, pâncreas e paredes do tubo digestivo; e eritrocitária predominantemente nos eritrócitos, neurônios e placas motoras; causando elevação nos níveis de acetilcolina. Esta enzima é responsável pelos impulsos nervosos nas junções colinérgicas sinápticas e neuromusculares. A elevação desses níveis gera uma Síndrome Colinérgica, caracterizada por sinais que envolvem o Sistema Nervoso Central (SNC) e ainda sintomas nicotínicos com estimulação excessiva de musculatura esquelética e muscarínicos onde há excessiva estimulação dos receptores das glândulas, ou seja, na musculatura lisa. ${ }^{(4,9,11,12)}$

O monitoramento de indivíduos intoxicados por organofosforados é feito através de exames laboratoriais, como as enzimas hepáticas Aspartato Transferase (AST), Alanina Transferase (ALT), Fosfatase Alcalina (FAL) e Gama Glutamil Transferase ( GT), e especificamente com a dosagem das colinesterases a Acetilcolinesterase (AChe) e a Butirilcolinesterase (BChe), com essa determinação pode-se estabelecer o tipo de intoxicação aguda ou crônica, de acordo com a variação da meia vida de cada enzima. ${ }^{(11,12,13)}$

O tratamento das intoxicações por organofosforados baseia-se principalmente no uso medicamentoso, sendo a Atropina, um antagonista dos efeitos da acetilcolina, e da Pralidoxima que reativa a enzima colinesterase e protege a que ainda não foi inibida pelo inseticida anticolinesterásico. ${ }^{(2,3,9)}$

Esse artigo buscou desenvolver um estudo sobre a importância da avaliação dos níveis séricos das colinesterases em casos de intoxicações por inseticidas. Por meio dele, pretendeu-se estabelecer um subsídio referencial teórico no acompanhamento e monitorização das alterações provocadas que auxiliará os profissionais da saúde e promover uma reflexão sistemática da população para a redução de possíveis novos casos.

O artigo foi realizado através da pesquisa bibliográfica de forma sistemática, abrangendo bibliografias públicas em relação ao tema estudado, como publicações de artigos científicos, monografias, dissertações e revistas eletrônicas, entre outras, localizadas em acervo digital através de sites relacionados. Sua finalidade é colocar o pesquisador em

Volume 2, Número 1 - Maio, 2016. 
contato direto com o que já foi estudado, escrito, dito ou afirmado sobre o determinado assunto, oferecendo meios para a exploração e reforço do mesmo.

O período de realização da pesquisa foi de fevereiro de 2014 a outubro de 2014, sendo que o período de publicação dos artigos utilizados variou entre os anos de 1996 a 2013. O levantamento bibliográfico deu-se através de buscas de produções indexadas no banco de dados da Biblioteca Virtual em Saúde (BVS-BIREME) na base eletrônica LILACS, assim como as indexadas na base eletrônica PubMed e Scielo.

As palavras Chave utilizadas foram: agrotóxicos, colinesterases, diagnóstico, intoxicação.

\subsection{INSETICIDAS}

A utilização de agrotóxicos no Brasil, se iniciou na década de 60 , pelo intenso e contínuo processo de mudanças tecnológicas e organizacionais no mundo da produção agrícola, esses produtos foram incluídos compulsoriamente, junto com fertilizantes químicos e adubos para melhoria na produtividade agroindustrial. ${ }^{(1)}$

O consumo desses produtos no Brasil cresceu significativamente nas últimas décadas, transformando o país em um dos líderes mundiais de utilização. Os danos para o organismo humano se iniciaram a partir daí, com isso casos intoxicados passaram a ser relatados devido ao fato da população rural estar despreparada ou seja, manipulavam os produtos sem proteção, sendo expostos a inúmeras substâncias potencialmente tóxicas, além da vasta degradação ambiental gerada pelo seu uso descontrolado. ${ }^{(4,14)}$

Os agrotóxicos são definidos como os produtos e os agentes de processos físicos, químicos ou biológicos destinados ao uso nos setores de produção, armazenamento e beneficiamento de produtos agrícolas, nas pastagens, na proteção de florestas nativas ou implantadas e de outros ecossistemas e também de ambientes urbanos, hídricos e industriais, com a finalidade de alterar a composição da flora e da fauna, afim de preservá-la da ação danosa de seres vivos considerados nocivos; substâncias e produtos empregados como desfolhantes, dessecantes, estimuladores e inibidores do crescimento. ${ }^{(5,8)}$

De acordo com a Organização Mundial de Saúde (OMS), esses compostos são separados em quatro categorias: Classe la (extremamente perigosos), Classe lb (altamente perigosos), Classe II (moderadamente perigosos) e Classe III (levemente perigosos) sendo

Volume 2, Número 1 - Maio, 2016. 
então reforçados pela simbologia cromática (vermelho, amarelo, verde e azul). Outra classificação é estabelecida de acordo com o mecanismo de ação, podendo ser herbicidas, fungicidas e inseticidas. ${ }^{(4,5)}$

Os fungicidas agem no combate a fungos, os herbicidas combatem ervas daninhas, sua utilização tem sido crescente na agricultura nos últimos 20 anos e os inseticidas possuem ação de combate a insetos, larvas e formigas, pertencente ao grupo químico dos organofosforados, sendo este o alvejado do estudo.(4,5)

Os inseticidas são utilizados em grande escala pelos setores produtivos e intensamente pelo setor agropecuário, para controle de pragas e vetores, eles se tornaram um dos mais importantes fatores de risco para o ser humano, pelos danos que provocam à saúde das populações e dos trabalhadores que os manuseiam. ${ }^{(8)}$

As intoxicações acidentais ou intencionais são importantes causas de agravo à saúde, estima-se que $1,5 \%$ a $3 \%$ da população intoxicam-se todos os anos. No Brasil isso é representado por cerca de 4.800 .000 casos novos a cada ano, sendo que $0,1 \%$ a $0,4 \%$ das intoxicações culminam em óbito.(16)

Entre os agrotóxicos mais utilizados encontram-se os compostos pertencentes à categoria dos organofosforados, que apresentam mecanismo de ação baseado na inibição de acetilcolinesterase e são responsáveis pelo maior número de intoxicações no meio rural. Dentre os aspectos que contribuem para a ocorrência de intoxicação, estão a falta de cuidado, de higiene, informação ou controle adequado durante a utilização destes produtos, associado ao acesso fácil e disponibilidade e condições inapropriadas de estocagem..$^{(9,17)}$

Devido à falta de fiscalização e a não aplicação de multas e sanções previstas, os produtores rurais não se importam em cumprir as práticas de manuseio e aplicação corretas, agem com descuido e descartam a necessidade do uso de equipamentos de proteção individual (EPI) mesmo sabendo ou não da gravidade da exposição aos agrotóxicos. ${ }^{(6,13)}$

No Brasil, a incidência de intoxicações por organofosforados mantém-se alta, apesar de ter reduzido em relação a década de 60 , período que o agrotóxico passou a ser utilizado de fato. Atualmente, o órgão responsável pelos registros de casos de intoxicações brasileiras é o SINITOX- Sistema Nacional de Informações Tóxico-Farmacológicas, composto por Centros de Informação e Assistência Toxicológica (CIT) distribuídos em 19 estados e no Distrito Federal. ${ }^{(2,4,7)}$

As principais vias responsáveis pelo impacto da contaminação humana por agrotóxicos são: via ocupacional, via ambiental e a via alimentar. A via de contaminação ocupacional se caracteriza pela contaminação dos trabalhadores que manipulam essas substâncias, tanto

Volume 2, Número 1 - Maio, 2016. 
no processo de formulação quanto no de utilização e na colheita, esta via é responsável por mais de $80 \%$ dos casos de intoxicação por agrotóxicos. ${ }^{(5,14)}$

A contaminação pela via ambiental caracteriza-se pela dispersão na distribuição do produto nos componentes do meio ambiente, a contaminação da atmosfera, a contaminação do solo, a contaminação das águas, através da migração dos resíduos de agrotóxicos para lençóis freáticos, leitos de rios, córregos e lagos próximos; a via alimentar está relacionada à ingestão de produtos contaminados por agrotóxicos, esta via atinge a maioria da população urbana, que são os consumidores. ${ }^{(5,14)}$

A exposição à organofosforados induz, em seres humanos, alterações bioquímicas e síndromes clínicas. Nos casos de intoxicação aguda, há a manifestação de sintomas muscarínicos, como bradicardia, dispneia, visão turva e náuseas, seguidos de sintomas nicotínicos como a sudorese, cãibras, taquicardia e tremores, ou mesmo manifestações do sistema nervoso central (SNC) incluindo cefaleia, convulsões, coma e morte. ${ }^{(17)}$

Os efeitos crônicos sobre a saúde humana, relacionados com exposições por longos períodos e em concentrações baixas, são de maior dificuldade de reconhecimento clínico, entre eles são descritos malformações congênitas, alterações imunológicas, genéticas, câncer, efeitos deletérios sobre o sistema nervoso, hematopoiético, respiratório, cardiovascular, hepático, pele e olhos, além de reações alérgicas e alterações

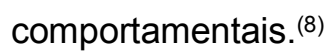

O monitoramento e controle de exposições a organofosforados é feito através da determinação da atividade colinesterásica no sangue dos trabalhadores, as colinesterases são marcadores biológicos de exposição aguda ou crônica, níveis reduzidos de sua atividade refletem alterações causadas por doenças crônicas ou por ação de agentes agressores como o caso destes compostos que atuam inibindo as acetilcolinesterases e butirilcolinesterases. $^{(1,2,11)}$

\section{RISCOS À SAÚDE DO TRABALHADOR}

Apesar do uso contínuo e da grande importância nas atividades agrícolas, os agrotóxicos, ainda não despertam muito interesse no estudo de aspectos e segurança na agricultura, há um interesse maior em desenvolver novas tecnologias para aumento da produtividade, geralmente esquecendo-se dos impactos à saúde e à segurança do trabalhador. ${ }^{(5)}$

Volume 2, Número 1 - Maio, 2016. 
Pode-se dizer que a realidade de trabalho notada na agricultura, especificamente no que se refere ao emprego de agrotóxicos, expressa as políticas de governo adotadas para o setor agrícola que priorizam a produtividade e se olvidam da proteção da saúde dos trabalhadores, e principalmente a maneira como esta tecnologia foi implantada no campo.(6,8)

Os mecanismos atuais de vigilância são inadequados para caracterizar os problemas de exposição tanto em relação a utilização do agrotóxico bem como de doenças relacionadas com os mesmos. Portanto, é aconselhável a limitação da exposição aos agrotóxicos e a utilização de produtos que apresentam toxicidade menor. Pode-se afirmar que as intoxicações e as doenças daí desencadeadas constituem um grave problema de saúde pública, no entanto poderiam ser reduzidos se as medidas de controle e de vigilância fossem mais ativas, e os setores responsáveis cumprissem com suas obrigações. ${ }^{(5)}$

Os agrotóxicos, para serem produzidos, exportados, importados, comercializados e utilizados devem ser previamente registrados em órgão federal, de acordo com as diretrizes e exigências dos órgãos federais responsáveis pelos setores da saúde, do meio ambiente e da agricultura.O IBAMA realiza a avaliação do potencial de periculosidade ambiental de todos os agrotóxicos registrados no Brasil.(18)

As notificações de intoxicações são feitas através da Rede Nacional de Centros de Informação e Assistência Toxicológica (Renaciat) que é coordenada pela Agência Nacional de Vigilância Sanitária (ANVISA), ela foi criada em 2005 pela Resolução da Diretoria Colegiada (RDC) $n^{\circ} 19$ da ANVISA, e é composta atualmente de 35 unidades e o distrito federal, tem como função fornecer informação e orientação sobre o diagnóstico, prognóstico, tratamento e prevenção das intoxicações e envenenamentos, assim como sobre a toxicidade das substâncias químicas e biológicas e os riscos que elas ocasionam à saúde.(19)

A ANVISA criou o Disque-Intoxicação, meio pelo qual os profissionais de saúde obtêm informações sobre tratamentos, além de o público em geral tirar dúvidas gratuitamente, por meio de uma rede de informações sistematizadas, é possível delinear um mapa da situação do país em relação à intoxicação. Os profissionais dos Centros de Informação e Assistência Toxicológica documentam os atendimentos prestados e encaminham as fichas para um banco de notificações. Posteriormente, as informações coletadas chegam à ANVISA e ao Sistema Nacional de Informações Tóxico-Farmacológicas (Sinitox). ${ }^{(19)}$

Devido à falta de fiscalização e a não aplicação das multas e penas, o produtor rural pouco se preocupa em informar aos seus trabalhadores das práticas de manuseio e 
aplicações corretas e da necessidade do uso de equipamento de proteção. $O$ aumento de risco de intoxicação pode estar associado à orientação passada pelo vendedor, este em muitas ocasiões não fornece informações devidas sobre utilização e compra do produto.(6)

Desse modo, as políticas de desenvolvimento do setor agropecuário e o processo de produção agrícola, devem se constituir de estudos e análises sobre o manuseio dos agrotóxicos pelos trabalhadores rurais, sendo necessária uma melhor apresentação das formas de utilização e da gravidade das exposições. ${ }^{(8)}$

\section{COLINESTERASES}

A colinesterase é uma enzima pertencente à família das esterases e é responsável pela degradação do neurotransmissor acetilcolina presente em terminações nervosas autonômicas pré-ganglionares (receptores nicotínicos), terminações parassimpáticas e algumas terminações nervosas simpáticas pós-ganglionares (receptores muscarínicos), junção neuromuscular (receptores nicotínicos), e em algumas sinapses do SNC.(11)

A acetilcolina é um neurotransmissor de pequenas moléculas de ação rápida, sintetizada no terminal pré-sináptico da acetilcoenzima A e da colina na presença da enzima colina acetilcolinesterase. Durante a transmissão sináptica neuronal na fenda sináptica, ocorre a liberação da acetilcolina, onde é rapidamente hidrolisada à acetato e colina pela enzima colinesterase, encontrada no reticulo de proteoglicanos existente no espaço da fenda sináptica. Novamente no terminal pré-sináptico, a colina é transportada ativamente de volta ao terminal para ser mais uma vez utilizada na síntese de uma molécula nova de acetilcolina. ${ }^{(3,10,20)}$

As colinesterases catalisam a hidrólise (destruição) da acetilcolina restante no espaço sináptico em colina e ácido acético, reação necessária para permitir que o neurônio colinérgico retorne a seu estado de repouso após a ativação, evitando assim uma transmissão excessiva de acetilcolina. Em casos de intoxicação por exposição à organofosforados, um valioso indicador é a determinação das colinesterases. ${ }^{(4,10)}$

A atividade das colinesterases é decorrente da ação de duas enzimas, a AchE ( acetil-colinesterase) a colinesterase eritrocitária , presente na membrana dos eritrócitos e outra sérica, BuChE (butiril-colinesterases) a colinesterase plasmática. A inibição destas enzimas, leva ao acúmulo de acetilcolina, e o organismo humano passa a apresentar uma série de manifestações indesejáveis. ${ }^{(6)}$

Volume 2, Número 1 - Maio, 2016. 
A acetilcolinesterase é sintetizada durante a hematopoese (processo de formação de células do sangue) e apresenta uma menor taxa de renovação sanguínea (cerca de noventa dias após o último contato com os organofosforados) do que a butirilcolinesterase que é uma enzima produzida no tecido hepático e exportada continuamente para a corrente sanguínea (em torno de uma semana após o último episódio) essa diferença possibilita a classificação das intoxicações, podendo revelar o tipo de exposição, aguda ou crônica.(21)

As intoxicações agudas podem ocorrer de forma leve, moderada ou grave, a depender da quantidade de agrotóxico, da via de contaminação (via ocupacional, ambiental ou alimentar), do tempo de absorção, da toxicidade do produto e do tempo decorrido entre a exposição e o atendimento médico. Manifestam-se através de um conjunto de sinais e sintomas, que se apresentam de forma súbita, alguns minutos ou algumas horas após a exposição excessiva aos agrotóxicos. Tal exposição geralmente é única e ocorre num período de até 24 horas, acarretando efeitos rápidos sobre a saúde..$^{(1,3,14)}$

As intoxicações crônicas surgem no decorrer de repetidas exposições ao agrotóxico, que normalmente ocorrem durante longos períodos de tempo. Os quadros clínicos são indefinidos, com dificuldades de associação entre a causa e o efeito principalmente quando há exposição a múltiplos produtos. Manifesta-se através de inúmeras patologias, que atingem vários órgãos e sistemas, com destaque para os problemas imunológicos, hematológicos, hepáticos e neurológicos. ${ }^{(1,3)}$

Considerando-se, que os níveis basais de colinesterase sofrem variações de uma pessoa para outra, o ideal é a determinação do valor pré-exposição de cada indivíduo para controle ocupacional de exposição a pesticidas organofosforados. Contudo esta determinação nem sempre é possível, então se sugere o uso de um valor de referência da atividade enzimática obtido de uma exposição não exposta.(11)

A inibição da enzima acetilcolinesterase conduz ao acúmulo de acetilcolina nas fendas sinápticas que, por consequência leva ao surgimento de uma Síndrome Colinérgica, caracterizada pela hiperestimulação do músculo esquelético, dos músculos lisos e das glândulas secretoras. Os sinais e sintomas mais comuns são os muscarínicos, com manifestações no sistema respiratório, gastrointestinal, urinário, cardiovascular, através de implicações nas glândulas exócrinas e sintomas oculares; os nicotínicos, com efeitos na musculatura estriada e gânglios simpáticos; e no SNC, com manifestações clínicas como cefaléia, ansiedade, agitação, tremores, coma e convulsões. ${ }^{(4,9,12)}$

O tratamento medicamentoso é eficaz e específico. A atropina antagoniza efetivamente os efeitos da acetilcolina e praticamente não exerce nenhum efeito ou

Volume 2, Número 1 - Maio, 2016. 
comprometimento neuromuscular periférico. A pralidoxima reativa a enzima colinesterase e resguarda a que ainda não foi inibida pelo inseticida anticolinesterásico. ${ }^{(2)}$

É importante salientar que a acetilcolinesterase pode ser inibida sem que, necessariamente ocorra intoxicação por agrotóxicos. Nesses casos, devem-se considerar a produção do fígado da butirilcolinesterase que apresenta uma atividade marcadamente afetada em diferentes patologias hepáticas, na desnutrição e em fatores endócrinos. Encontram-se diminuídas durante a gravidez, na hipocolesterolemia, alcoolismo, cirrose hepática, tuberculose, dermatomiosite, artrite reumatoide, anemias, infecções agudas e durante o uso de fenotiazínicos, sendo que algumas drogas também levam a essa redução como os sulfatos, fluoretos, citratos e codeínas. ${ }^{(10)}$

\section{DIAGNÓSTICO}

Considerando que o principal mecanismo de ação dos organofosforados é a inibição das colinesterases, e que sua ampla utilização provoca impactos na saúde humana, é imprescindível que se faça um monitoramento das pessoas envolvidas com esses compostos, para obter um diagnóstico do tipo de exposição para proceder com o tratamento adequado. ${ }^{(4)}$

O diagnóstico de indivíduos intoxicados por organofosforados é feito através de exames laboratoriais, como a dosagem das colinesterases (Ache e BChe), em conjunto com enzimas hepáticas Aspartato Transferase (AST), Alanina Transferase (ALT), Fosfatase Alcalina (FAL) e Gama Glutamil Transferase ( GT). As transaminases estão presentes em vários tecidos e a AST é encontrada no citosol e na mitocôndria dos hepatócitos. As enzimas GT e FAL são marcadoras de processos colestásicos e importantes no diagnóstico das hepatopatias pois encontram-se elevadas, a FAL é secretada pelo hepatócitos e pelas células da mucosa do trato biliar e a GT está distribuída em vários tecidos, mas a maior porção localiza-se nos canalículos das células hepáticas e nas células epiteliais dos ductos biliares. ${ }^{(13)}$

Linares et. al., estudando 20 municípios no Estado do Rio Grande do Sul, utilizaram amostras de sangue de 60 agricultores compondo o grupo exposto, e no controle foram colhidas 15 amostras de sangue de pessoas não expostas a organofosforados, sediadas na zona urbana da cidade, afim de obter-se os valores de referências locais de AChe e BChe. Após a determinação individual de AChe e BChe pelo método de Ellman modificado, verificou-se que 15 (25\%) evidenciaram níveis abaixo dos valores de referência de BChe,

Volume 2, Número 1 - Maio, 2016. 
similarmente, de acordo com os valores de referência de AChe os 60 (100\%) agricultores evidenciaram níveis inferiores em relação ao grupo controle. ${ }^{(17)}$

Já Almeida et.al., obtiveram resultados da atividade enzimática da acetilcolinesterase (Ache) em amostra de 61 pacientes, utilizando-se o método colorimétrico, a acetilcolinesterase sérica hidrolisa propioniltiocolina, com liberação de grupo sulfídrico livre ao nível de tiocolina. O grupo de sulfídrico livre reage levando a formação do ácido 5-tio-2nitrobenzóico, de cor amarela, medido numa absorção de 410 nm. Observou-se nos resultados, que 95\% dos valores foram considerados normais, que variam de 6,1 a 12,1 Ul. Desses, $4 \%$ apresentaram inibição e $2 \%$ aumento da atividade enzimática.(13)

No trabalho de Moreira et. al., os valores médios obtidos no estudo de um grupo não exposto, foram utilizados para estabelecer um valor significativo abaixo do qual os indivíduos seriam considerados possuidores de baixa atividade enzimática, característica esta observada nos casos de superexposição aos organofosforados. Para estabelecer o limite inferior, o cálculo utilizado foi equivalente a média - 1.645s.d., correspondendo a 0.47 UI para AChe e 2.32 UI para BChe. No conjunto de resultados estudados, houve redução de $11 \%$ da atividade AChe e de $12 \%$ da BChe. Os dados do presente trabalho estão apresentados na Tabela 1.(14)

\begin{tabular}{|l|l|l|}
\hline Grupo/Enzima & AChe & BChe \\
\hline $\begin{array}{l}\text { Não-expostos }{ }^{(1)} \\
\mathrm{n}=308\end{array}$ & $1.00 \pm 0.32$ (média $\pm \mathrm{p})$ & $4.00 \pm 1.02$ (média $\pm \mathrm{p})$ \\
\hline $\begin{array}{l}\text { Adultos expostos }{ }^{(1)} \\
\mathrm{n}=101\end{array}$ & $\begin{array}{l}1.005 \pm 0.28 \text { (média } \pm \mathrm{p}) \\
\text { Cl } 95 \%(0.94-1.06)\end{array}$ & $\begin{array}{l}3.77 \pm 1.01 \text { (média } \pm \mathrm{p}) \\
\text { Cl 95\%(3.56-3.97) }\end{array}$ \\
\hline $\begin{array}{l}\text { Valores de referência(média }- \\
1.645 \mathrm{p})\end{array}$ & 0,47 & 2,32 \\
\hline $\begin{array}{l}\% \text { de trabalhadores com baixa } \\
\text { atividade enzimática }\end{array}$ & 11 & 12 \\
\hline $\begin{array}{l}\text { Valores de Referência } \\
\text { Crianças/jovens }\end{array}$ & 30.1 (st dev $=3.87)$ & 2.26 (st dev $=0.55)$ \\
\hline $\begin{array}{l}\text { \% de crianças/jovens com } \\
\text { baixa atividade enzimática }\end{array}$ & Nenhum & 17 \\
\hline
\end{tabular}

Tabela 1:Valores de AChe e BChe encontrados em adultos e crianças moradores da região da Microbacia do Córrego de São Lourenço. (1) Método de dosagem: Ellman modificado por Cunha, J. C. (1996). Resultados expressos em unidades internacionais.

Volume 2, Número 1 - Maio, 2016. 
(2) Método de dosagem: EQM Test Kit - EQM Research Inc, Cincinati - Ohio. Resultados expressos em unidades internacionais por $\mathrm{ml}$ de sangue total (atividade de colinesterase plasmática) ou por grama de hemoglobina (atividade de acetilcolinesterase eritrocitária). Valores normais são considerados equivalentes $a \geq 75 \%$ em relação aos valores obtidos em uma população de referência $(n=40)$ apresentados no estudo de validação descrito no manual do kit.

Não obstante ao que Moreira et. al. observou,Cavaliereet. al., utilizaram animais (ratos albinos machos e fêmeas da linhagem Wistar) e na determinação da atividade da colinesterase plasmática foram colhidas amostras de $1 \mathrm{ml}$ de sangue por punção do plexo retro-orbitário, 24hs após o último tratamento com Paraoxon (organofosforado), atropina e pralidoxima. O plasma foi separado por centrifugação a 2000rpm por 15 minutos, e a atividade da colinesterase foi determinada pelo método espectrofotométrico de Ellman, 1961 modificado por Wilheim, 1967. O substrato utilizado foi a acetiltiocolina e a atividade enzimática foi determinada a pela variação de absorbância/ml/minuto, sendo feitas as leituras no comprimento de onda de $430 \mathrm{~nm}$. Os dados estão acima estão dispostos na Tabela 2.

\begin{tabular}{|c|c|c|c|c|}
\hline & $\begin{array}{l}\text { Grupo } 1 \\
\text { Paraoxon }\end{array}$ & $\begin{array}{l}\text { Grupo } 2 \\
\text { Paraoxon } \\
+ \text { atropina }\end{array}$ & $\begin{array}{l}\text { Grupo } 3 \\
\text { Paraoxon } \\
+ \text { pralidoxima }\end{array}$ & $\begin{array}{l}\text { Grupo } 4 \\
\text { Controle }\end{array}$ \\
\hline $\begin{array}{l}\text { Atividade } \\
\%\end{array}$ & $\begin{array}{l}0,48+0,092 \\
32,2\end{array}$ & $\begin{array}{l}0,65+0,124 \\
43,8\end{array}$ & $\begin{array}{l}1,38+0,241 \\
94,1\end{array}$ & $\begin{array}{l}1,46+0,133 \\
100,0\end{array}$ \\
\hline
\end{tabular}

Tabela 2: Valores de atividade da colinesterase plasmática e os desvios-padrão encontrados. ${ }^{(2)}$

Nos resultados observou-se que os animais tratados com paraoxon (grupo 1) e paraoxon mais atropina (grupo 2) apresentaram resultados de atividade da colinesterase de $32,2 \%$ e $43,8 \%$, respectivamente; revelando diferenças estaticamente significativas em relação ao grupo controle. Já os animais tratados com paraoxon mais pralidoxima (grupo 3) apresentaram atividade da colinesterase de $94,1 \%$, não havendo diferença significativa em relação ao grupo controle. ${ }^{(2)}$

Divididos em quatro grupos para estudo, Soares et. al., observaram o trabalho rural e uso de agrotóxicos. O primeiro grupo estava relacionado às características do entrevistado: sexo, nível de escolaridade, idade, ocupação no trabalho e relação de trabalho. O segundo estava relacionado aos dados do estabelecimento rural onde o Volume 2, Número 1 - Maio, 2016. 
trabalhador exercia sua atividade: área total e cultivada. O terceiro era aquele associado ao uso de agrotóxicos; horas/dia e dias/mês de exposição aos agrotóxicos, tipos de produtos mais empregados, citando organofosforado ou carbamato, utilização do equipamento de proteção, orientação de uso e local de compra do produto, tipo de contato com agrotóxico, e conhecimento do perigo relacionado ao uso de agrotóxicos. Oúltimo grupo indicava o estado de saúde do trabalhador,representado pela dosagem de colinesterase.(6)

$\mathrm{Na}$ dosagem da colinesterase, foi utilizado o método de Edson e utilizou-se o kit Loivi-Bond como processo colorimétrico, esse método permite a determinação da atividade colinesterásica de forma rápida, com custo reduzido e sem necessidade de equipamentos sofisticados, o valor da atividade da colinesterase sanguínea, é expresso em porcentagem da atividade do sangue normal, se concentrando na avaliação percentual da BChe. Nos resultados observou-se que aproximadamente $50,3 \%$ dos indivíduos encontravam-se intoxicados, $367(34,5 \%)$ e $161 \quad(15,2 \%)$ dos indivíduos pesquisados estavam respectivamente com $87,5 \%$ e $100 \%$ de atividade colinérgica, sendo considerados não intoxicados. No caso dos intoxicados, 388 (36,5\%), 132 (12,4\%) e 14 (1,3\%) estavam com níveis de atividade de colinesterase de $75 \%, 62,5 \%$ e $50 \%$ respectivamente. ${ }^{(6)}$

Estudos realizados no Iran, em trabalhadores de uma indústria de pesticidas, e através do método de Ellman obtiveram valores médios para atividade colinesterásica inicial de 48+- $11 \mathrm{Ul} / \mathrm{g}$ de hemoglobina e 9.569 +- $2.496 \mathrm{UI} / \mathrm{L}$, para AChe e BChe, respectivamente. ${ }^{(10)}$ Portanto foi observado que os estudos acima apesar de utilizarem metodologias diferentes evidenciaram uma redução das atividades enzimáticas.

Estudos realizados na Índia, por Chakraborty et. al., com agricultores que pulverizavam os campos com pesticidas dos grupos organofosforados e carbamatos, utilizou-se para a determinação das colinesterases o método de Ellman e os resultados obtidos no grupo controle foram de 4.604+- $690 \mathrm{UI} / \mathrm{L}$ e o valor médio para AChe foram de 754+- 42 UI/L. ${ }^{(22)}$

Também foi observado por Soarez-Lopez et. al., em estudo no Equador, os efeitos dos pesticidas anticolinesterásicos entre as crianças que vivem com trabalhadores de plantação de flores, comparando os valores de um grupo não exposto, sendo o valor médio da $A C h e$ de $3,22 \mathrm{U} / \mathrm{mL}$, esse valor levou a hipótese de que a quantidade de pesticidas que os trabalhadores levavam para casa eram suficientes para diminuir a atividade colinesterásica das crianças. ${ }^{(23)}$

Em estudo na Carolina do Norte, novamente foram verificadas reduções dos níveis de atividade colinesterásica em toda a campanha agrícola, sendo as diminuições $>15 \%$ do

Volume 2, Número 1 - Maio, 2016. 
valor mais alto de um indivíduo, identificando e considerando uma redução da atividade colinesterásica significativa. ${ }^{(24)}$

Uma avaliação das atividades de AChe e BChe realizadas em trabalhadores agrícolas da Índia, mostraram uma redução significativa nas atividades de $14 \%$ e 56\%, respectivamente. Os valores foram obtidos através do método de Ellman modificado, na AChe controle os resultados variaram de 2,22 a 3,51 umoles $/ \mathrm{min} / \mathrm{ml}$ e para os indivíduos expostos variaram de 1,65 a 3,54 umoles $/ \mathrm{min} / \mathrm{ml}$. Para a BChe controle os resultados foram entre 2,19 a 5,06umoles $/ \mathrm{mim} / \mathrm{ml}$ e em indivíduos expostos de 0,16 a 5,2 umoles $/ \mathrm{min} / \mathrm{ml}$.(12)

Os resultados descritos demonstraram uma diminuição significativa dos níveis das colinesterases, em casos de exposições aos organofosforados, observando-se que quanto menor o nível da atividade enzimática, maior o grau das intoxicações, sendo que a melhor forma de prevenção é o diagnóstico e o monitoramento dos casos.

Sabe-se que muitos dos casos não são notificados, devido à falta de políticas efetivas de fiscalização, controle, acompanhamento e aconselhamento técnico apropriado na utilização dos compostos.

\section{CONSIDERAÇÕES FINAIS}

O alto poder tóxico dos organofosforados pode ser evidenciado através da diminuição das atividades colinesterásicas, assim como a exposição continuada a eles e as inúmeras e graves intoxicações, nos comete a refletir que este assunto merece ser incluído nas prioridades de saúde, com o planejamento e a execução da assistência em área rural e urbana. ${ }^{(12)}$

Além dos trabalhadores, os consumidores também sofrem a contaminação através dos resíduos de pesticidas em frutas e hortaliças, colocando em risco a sua saúde, por isso se torna necessário à adoção de políticas que invistam na qualidade de vida humana e não só na produtividade agrícola. ${ }^{(1,3,14)}$

Portanto, é necessário o maior emprego de normas de segurança, como a utilização de EPI's durante o manuseio dos produtos, fortalecimento nos sistemas de notificações e informações aos agricultores sobre os organofosforados, realização de monitoramento e acompanhamento dos níveis das colinesterases de agricultores, por meio de exames laboratoriais, onde o biomédico se insere, para prevenção, diagnóstico e melhoramento da qualidade de vida, relacionada à saúde dos trabalhadores, evitando possíveis complicações.

\section{REFERÊNCIAS}

Volume 2, Número 1 - Maio, 2016. 
1. ARAUJO, A. J. de; LIMA, J.S. de; MOREIRA, J.C. Exposição múltipla a agrotóxicos e efeitos a saúde: estudo transversal em amostra de 102 trabalhadores rurais. Nova Friburgo, R.J. Revista ciência e saúde coletiva, 2007, p.115-130.

2. CAVALIERE, MJ. et al. Miotoxicidade por organofosforados . São Paulo, Rev. SaúdePública, v30 (3), 1996, p.267 - 272.

3. RIBEIRO, Amanda Cavalari Cotrim; MELLA, Eliane Aparecida Campesatto. Intoxicação ocupacional por organofosforados-a importância da dosagem de colinesterase. Iniciação Científica Cesumar, v9(2), 2007, p.125-134.

4. BRUM, B. C. Anticorpos aviários como reagentes para o diagnóstico da intoxicação humana por organofosforados. Dissertação apresentada para obtenção do título de mestre em ciências na área de saúde pública. Universidade Federal do Rio de Janeiro, UFRJ, 2010, $47 \mathrm{f}$.

5. DOMINGUES, M. R., BERNARDI, M. R., ONO, E.Y.S, ONO, M.A, Agrotóxicos: risco à saúde do trabalhador rural.Semina: Ciências biológicas e da saúde, Londrina, v. 25, jan./dez. 2004, p. 45- 54.

6. SOARES, W; ALMEIDA, R.M.V.R; MORO, S. Trabalho rural e fatores associados ao regime de uso de agrotóxicos em Minas Gerais, Brasil. Cad. Saúde Pública, Rio de Janeiro, jul-ago, 2003, p. 19(4): 1117 - 1127.

7. FARIA, N.M.X. et al. Intoxicação por agrotóxicos no Brasil: os sistemas oficiais de informação e desafios para a realização de estudos epidemiológicos. Ciência e Saúde Coletiva, 12 (1), 2007, p. 25 - 38.

8. SILVA, J. M. et al. Agrotóxico e trabalho: uma combinação perigosa para a saúde do trabalhador rural. Ciência \& Saúde Coletiva, v.10(4), 2005, p. 891- 903.

9. OLIVEIRA, M. L. F de; BURIOLA, A. A. Gravidade das intoxicações por inseticidas inibidores das colinesterases no noroeste do estado do Paraná, Brasil. Revista Gaúcha Enferm., Porto Alegre (RS), 2009, p.648-655.

Volume 2, Número 1 - Maio, 2016. 
10. AHMADI, A.R; MANSOURIAN, A.R. Effects of occupational exposure in pesticide plant on workers' serum and erythrocyte cholinesterase activity. Int J Occup Med Environ Health. 2.007, v.20(4); p.381-5.

11. CÂMARA, S.A.V, et al. Exposição a agrotóxicos: determinação dos valores de referência para colinesterase plasmáticae eritrocitária. Brasília Med; v.49 (3), 2012, p. 163-169.

12. DHANANJAYAN, V., et al. "Assessment of acetylcholinesterase and butyrylcholinesterase activities in blood plasma of agriculture workers." Indian journal of occupational and environmental medicine, 16(3), 2012, 127.

13. ALMEIDA, C.G de, et al. Enzimas hepáticas e acetilcolinesterase como biomarcadores de efeito dos agrotóxicos utilizados na cultura do Alliumsativum, Revista Biociências, Unitau. V.14(2), 2008, p. 117-126.

14. MOREIRA, Josino C. et al. Avaliação integrada do impacto do uso de agrotóxicos sobre a saúde humana em uma comunidade agrícola de Nova Friburgo, RJ. Ciênc. saúde coletiva. 2002, v.7(2), p. 299-311.

15. LAKATOS, et al; Fundamentos de metodologia científica. $3^{a}$ Ed. São Paulo: Atlas, 1997, p. 270.

16. JESUS, H.S, BELTRÃO, H.B.M, ASSIS, D.M. Avaliação do sistema de vigilância das intoxicações exógenas no âmbito da saúde do trabalhador no Brasil entre 2007 e 2009. Cad. Saúde Colet., Rio de Janeiro, 2012, v.20 (4), p. 515-524.

17. LINARES, C.E.B, et al. Níveis basais de acetilcolinesterase e butirilcolinesterase em agricultores da região de Frederico Westphalen - RS. Rev. Saúde, v.31 (1-2), 2005, p.47- 51.

18. MINISTÉRIO DO MEIO AMBIENTE: Segurança Química: agrotóxicos. Disponível em: <http://www.mma.gov.br/seguranca-quimica/agrotoxicos>. Acesso em: 15 set. 2014.

Volume 2, Número 1 - Maio, 2016. 
19. SINITOX: Centros de informação, 2013. Disponível em: <http://www.fiocruz.br/sinitox_novo/cgi/cgilua.exe/sys/start.htm?sid=6>. Acesso em: 15 set. 2014.

20. Guyton, A. C. e Hall, J.E. Tratado de Fisiologia Médica, $12^{a}$ Edição. Editora Elsevier, 2011.

21. OLIVEIRA-SILVA, J.J, et al. Influência de fatores socioeconômicos na contaminação por agrotóxicos, Brasil. Rev. Saúde Pública, 2001, v.35 (2), p. 130135.

22. CHAKRABORTY, SREEPARNA, et al. "Chronic exposures to cholinesteraseinhibiting pesticides adversely affect respiratory health of agricultural workers in India."Journal of occupational health.v.51(6), 2009: 488-497.

23. SUAREZ-LOPEZ, JOSE R., et al. "Lower acetylcholinesterase activity among children living with flower plantation workers." Environmental research. V.114, 2012: 53-59.

24. QUANDT, S. A., et al. "Cholinesterase depression and its association with pesticide exposure across the agricultural season among Latino farmworkers in North Carolina." Environmental health perspectives.v.118(5), 2010: 635.

Volume 2, Número 1 - Maio, 2016. 